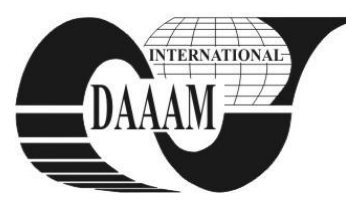

Annals of DAAAM for 2011 \& Proceedings of the 22nd International DAAAM Symposium, Volume 22, No. 1, ISSN 1726-9679 ISBN 978-3-901509-83-4, Editor B. Katalinic, Published by DAAAM International, Vienna, Austria, EU, 2011 Make Harmony between Technology and Nature, and Your Mind will Fly Free as a Bird

\title{
APPROACH TO THE WELDING CABLE BUNDLE 3D MODELLING FOR OFF-LINE PROGRAMS APPLICATION
}

\author{
KUMICAKOVA, D[arina]
}

\begin{abstract}
This paper presents some results of solution of offline programs chosen problem. The attention is aimed at the welding applications and problem of the welding cable bundle collision states detection during simulation in framework offline program virtual environment. Our work relates to solution of problem of $3 D$ modelling and simulation of cable bundle as a flexible element. We used spline-based procedure for the cable $3 D$ modelling. The simplified $3 D$ model representations were created. Their collision states were verified in virtual environment of chosen CAx system. The proposal of the methodology of the welding cable bundle collision state detection for specified off-line program is described briefly too. Key words: welding robots, off-line programming, cable bundle $3 D$ modelling
\end{abstract}

\section{INTRODUCTION}

At the present two ways of production machines and robots programming are used - "on-line" and "off-line" programming. On-line programming is executed by direct guiding robot arm through points of required trajectory from the programming panel (Teach Pendant). The advantage of this programming method is a work at the real automated workplace. Off-line programming enables to describe the task complexly, to make an experiment with structure of workplace, to eliminate a collision states and to verify a created program in 3D form. Offline programming goes out from the accurate 3D model of working cell. There non-standard programming languages are used and that is why the compiler is required for robot program creating. Every virtual model of robot consists of models of the robot 3D solid model, control unit (real control unit of robot) and program (specification of the robot task). Simulation can run in real time. Optimal variant of program is compiled into robot language and then it is imported into real robot system. The practical utilisation of robot off-line programming has brought some problems what have to be solved (Kovacic \& Kumicakova; 2010):

- Robot workplace calibration

- Precision of robot 3D model in comparison with real robot

- Collision states of cable bundles during simulation

- Robot singularities

- Simultaneous control of external axes

The detection of flexible cable bundles collision states during simulation are problem of high importance. The present off-line programs haven't solved up this problem till this time.

\section{FLEFIBLE ELEMENTS 3D MODELLING}

Welding cable bundles (Fig. 1) are flexible elements that change their shape in spatial in dependency of the welding robot arm movements. It is difficult to predict how the cable bundle will behave (spatially bend and deflection) at the specific welding task executed by the robot and therefore the simulation of its collision states is problematic. 3D modeling of cable bundle is one of problems of off-line programs real-time simulation and is still in process of its solution.

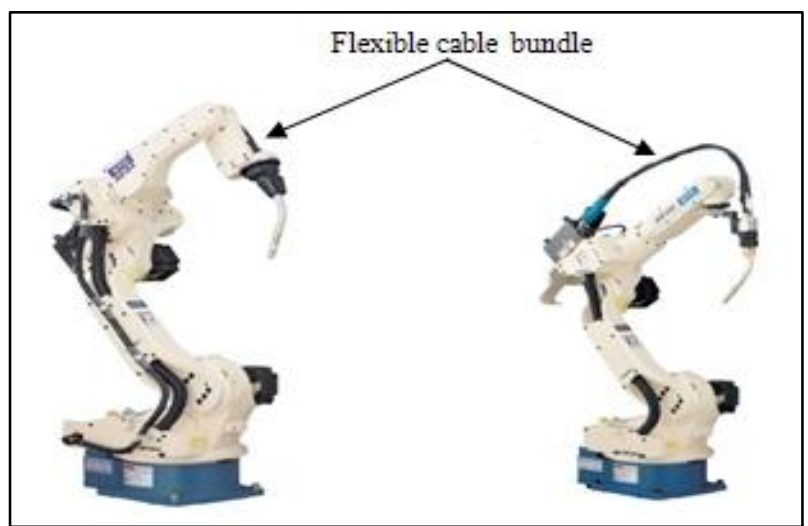

Fig. 1. Welding robots with cable bundle guide by: a) robot wrist interior (AII-B4) or b) robot arm exterior (AII-V6), OTC Daihen (http://robotec.sk/)

3D modeling and simulation of flexible elements (cables or hoses) has been of big interest in automotive and air industry most of all. Many approaches to automation of this process were presented till this time. The most of flexible bodies simulations use only a few basic simulation methods: finitelement method, spline-based procedure, mass-spring system, inverse kinematic on joint chains (Hergenröther \& Dähne, 2000), etc. The extended spring-mass system solved with an energy minimizing algorithm was described in (Gregoire \& Schömer; 2007). Some virtual reality systems have been developed to aid cable harness designers. Iowa State University has been developed a prototype virtual reality system (VRHose) for routing flexible hoses. This one provides good integration with CAD and routes hoses along B-spline curves (Holt et all.; 2004). The time needed for calculation of B-spline interpolations and the additional time taken by the ADAMS package was constrained in its real-time design and editing ability.

\subsection{D modeling of welding cable bundle}

The welding cable bundles consist of both rigid and flexible elements (Fig. 2). Just coaxial power cable is damaged in collision with weldment most of all. Cable bundles are of different type in dependency of their usage. Their main abilities can be described as follows: constant length for one type of cable, undeformable cross section and mass of each segment is the same along the entire cable. The present approaches to this type of flexible element 3D modeling are based on the modeling of string of $m$-rigid bodies connected to each other by $m-1$ specified joints. These models represent dynamically constrained systems and are of a high number of DOFs. Now they are not yet suitable for implementation into off-line 
program for welding cable bundle collision states simulation in framework of the complex welding workplace virtual model.

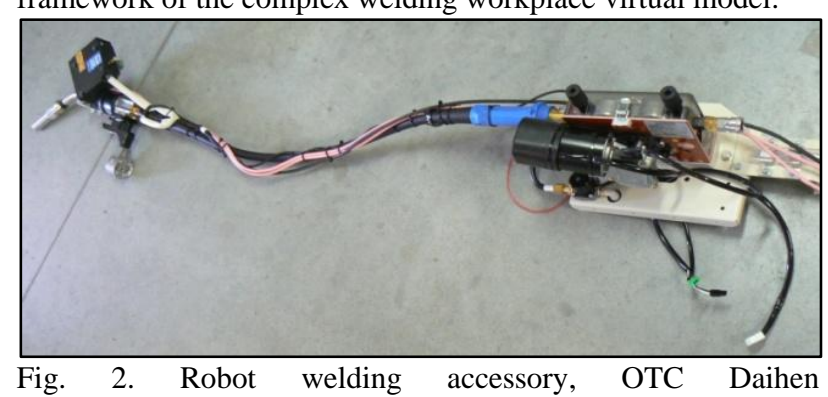

(http://robotec.sk/)

Our approach is to use a method of spline and patch modelling for creation of 3D model representation of welding cable bundle for its real-time simulation. The welding robot AII-V6 equipped with cable bundle for the MIG/MAG welding method and water-cooled welding torch and big CAD system Solid Works were chosen for verification of proposed way of the cable bundle 3D modelling. The new approach (Kovačič, 2011) is in creation of cable bundle simplified 3D model representations. These ones consist of the specified critical areas of the real welding cable bundle that are most often devastated at collisions states between the cable bundle and weldment in the real welding workplace conditions. The parameters of the spline courve parametric representation were specified. The weighted control points were defined and interpolation spline was created - see example of one of the cable bundle 3D model representations in Fig. 3.

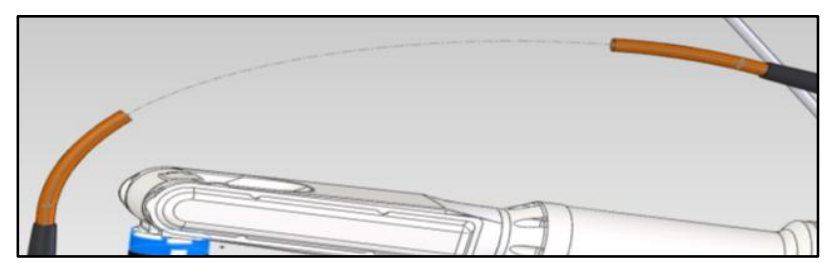

Fig. 3. Defined interpolation spline (Kovačič, 2011)

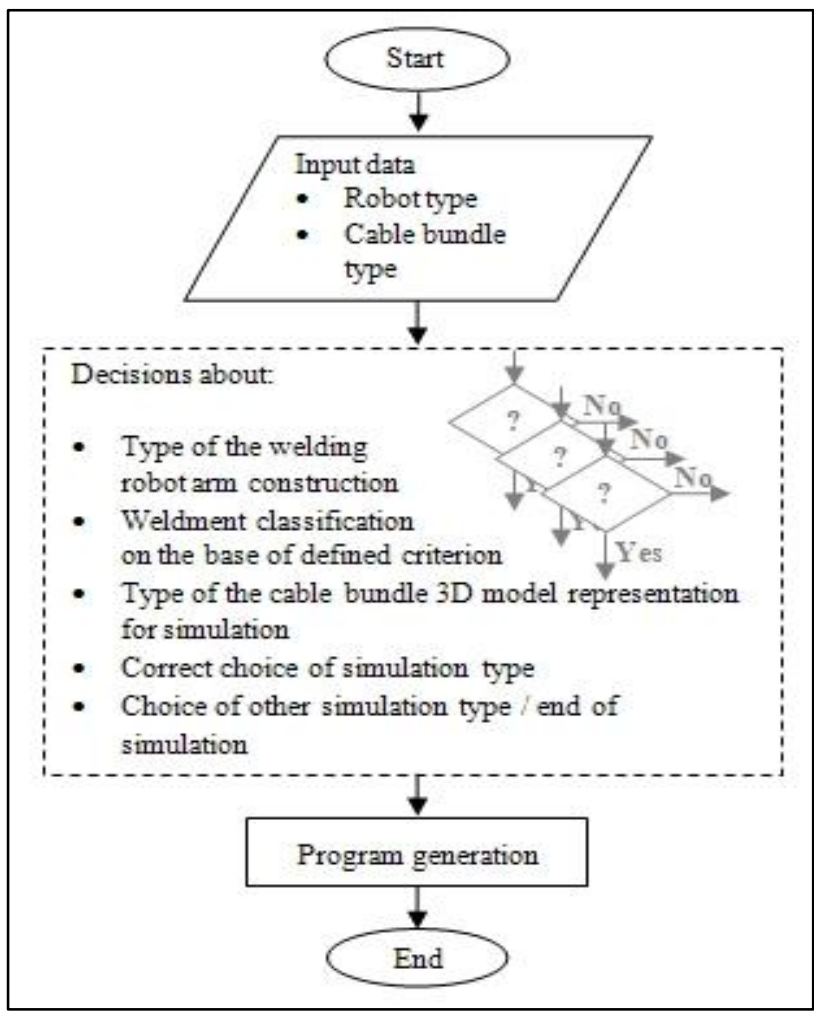

Fig. 4. Simplified algorithm of the proposed methodology
Four types of 3D model representations were created and verified by simulation in environment of big CAD system Solid Works. The proposal of algorithm of methodology of the welding cable bundle collision state detection in off-line program was created in (Kovacic, 2011) too. The criterions for the weldment classification were specified and the theorems for the type of cable bundle 3D model representation choice were formulated. The proposed methodology was created for the specific off-line programme and therefore only simplified form of its algorithm is presented in Fig. 4.

\section{CONCLUSION}

The main target of our work was to purpose suitable way of the flexible welding cable bundle 3D modelling for real-time simulation in welding workplace virtual model in off-line program. The analysis of known approaches to the flexible body 3D modelling and simulation was done. The method of spline and patch modelling was used for creation of the welding cable bundle 3D model representations for the specified application. Simulation of collision states between the cable 3D model representation and weldment was done in system Solid Work successfully. Results of simulations showed that these 3D model representations are suitable for real-time simulation. Because common user cannot do any functional modification in off-line program we couldn't verify our proposal in frame the one. Therefore one of the future tasks will be to review the proposed approach to the creation of the cable bundle 3D model representations by producer of chosen off-line program and evaluate a possibility of this one for the collision states detection in real-time simulation.

The main steps of the proposed methodology of collision states detection can be helpful in creation of this new tool of off-line program. The proposed methodology is applicable for any off-line programme and is opened to its next improvements. For example the weldment classification could be worked out with utilization advanced methods based on the similarity principles.

\section{ACKNOWLEDGEMENTS}

This article was prepared partially thanks to the cooperation between our department and company robotec, s.r.o. in framework of the dissertation thesis solution and partially with aid of grant MS SR 054ŽU- 4/2011.

\section{REFERENCES}

Gregoire, M. \& Schömer, E. (2007): Interactive Simulation of One-Dimensional Flexible Parts. Available from: http://www.sciencedirect.com/science/article/pii/S0010448 507001169

Hergenröther, E. \& Dähne, P. (2000): Real-Time Virtual Cables based on Kinematic Simulation, Available from: http://citeseerx.ist.psu.edu/viewdoc/download?doi=10.1.1.1 42.334

Holt, P., Ritchie, J., Day, P., Simmons, J., Robinson, G., Russel, G. \& Ng, F. (2004): Immersive virtual reality in cable and pipe routing: Design metaphors and cognitive ergonomics. Available from: http: //www.costar.hw.ac.uk/ publications/ 2004_JCISE_Journal.pdf

Kovačič, P. - Kumičáková, D. (2010): Problems of off-line programs of robots for welding applications. In: Journal CA systems in production planning. Vol. 11 , No. 2/2010, p. 1923, ISSN 1335-3799

Kovačič, P. (2011): The proposal of methodology of the collision states solution in framework of the welding robots "off-line" programming. Dissertation thesis, University of Žilina, Faculty of Mechanical Engineering, 2011, pp. 121

*** (2011) http://www.robotec.sk/ 